\title{
Reflection on studies on the learning process in problem-based learning
}

\author{
Diana H. J. M. Dolmans • LuAnn Wilkerson
}

Received: 3 August 2011/Accepted: 3 August 2011/Published online: 23 August 2011

(C) The Author(s) 2011. This article is published with open access at Springerlink.com

\section{Introduction}

In this special issue, seven studies are reported on problem-based learning (PBL). Two studies deal with the PBL process and especially the three PBL phases of initial problem discussion, self-study and reporting. Five other studies report on factors influencing students' learning in PBL: the PBL problem, the tutor, and two other scaffolds, worksheets and a reflection journal. The studies were conducted in a setting in which a specific approach to PBL was used, the so called-one-day-one-problem approach to PBL. In this reflection on the studies reported in this special issue, first of all the unique one-day-oneproblem approach to PBL will be explained. Thereafter the findings of the studies reported in this special issue will be summarized, after which the strengths and weaknesses of the studies are reported, as well as suggestions for further research and educational practice.

\section{The one-day-one-problem approach to PBL in short}

The studies were conducted in a Polytechnic in Singapore established in 2002, offering 3 -year degree programs to 17 years old students who finished secondary education and who had no experience with problem-based learning when they enter this school. The programs include life sciences, health sciences, engineering and information technology. Each day one problem is covered by the students in five teams of five students guided by one tutor and working in one large room. The students meet three times each day, 5 days a week. During the first meeting of approximately $1 \mathrm{~h}$ each team discusses the problem and

\footnotetext{
D. H. J. M. Dolmans ( $₫)$

Department of Educational Development and Research, School of Health Professions Education (SHE), Faculty of Health Medicine and Life Sciences (FHML), Maastricht University, PO Box 616, 6200 MD Maastricht, The Netherlands e-mail: D.Dolmans@maastrichtuniversity.nl

L. Wilkerson

University of California, Los Angeles, UCLA, USA

e-mail: LWilkerson@mednet.ucla.edu
} 
generates learning issues. The tutor does not join any individual group but is available to clarify and facilitate the introduction of the problem. This is followed by a self-study period of $4 \mathrm{~h}$ during which students search for literature and complete structured worksheets either individually or with others from their team. During this period, each team also reconvenes to meet with the tutor for $20 \mathrm{~min}$ to see whether team members are on the right track and to reformulate the learning issues, if necessary. Subsequently the study period continues. Thereafter the teams meet again, this time for $2 \mathrm{~h}$. The team members first discuss the results of their individual study and prepare a summary of their findings. Each team then presents its findings to the entire class for a discussion facilitated by the tutor. The next day, the same procedure is followed for a new problem. The problem and study materials are made electronically available to the students (Rotgans et al. 2011).

\section{Study findings}

What are the findings of the studies reported in this special issue? The first study demonstrates that all PBL phases-initial problem analysis, self-study and reporting-are important for students' learning in terms of relevant concepts that are recalled and that the recall of relevant concepts at the end of the reporting phase is positively related with students' achievement (Yew et al. 2010). The findings of the second study show that students' cognitive engagement increases over the PBL phases each day, because students have gained more knowledge about the topic under discussion (Rotgans and Schmidt 2011). Overall, it can be concluded from the two studies that the PBL process and especially all the three PBL phases enhance students' recall of concepts, students' cognitive engagement and students' achievement.

The other five studies focus on factors influencing students' learning, such as the PBL problem, problem worksheets, and the tutor. The third study focuses on PBL problems, demonstrating that a clearly formulated problem with clear problem statements has a positive influence on the group discussion. The group discussion is more focused and leads to a clear list of learning issues, which subsequently has a positive influence on self-study and academic achievement (Sockalingam et al. 2011). The fourth and fifth studies deal with the influence of the tutor. The fourth study demonstrates that the tutor's social congruence, i.e. the tutor's ability to communicate informally with the students and the tutor's ability to make students feel comfortable to ask questions, has a significant impact on concepts recalled by the students during all three PBL phases and on student achievement. The tutor's cognitive congruence, i.e. whether the students could understand the tutor, and the tutor's subject-matter expertise had no significant impact on concepts recalled during the three PBL phases, although they both had a significant impact on student achievement (Chng et al. 2011). The fifth study, shows that students' evaluations of a tutor's social congruence, cognitive congruence and expertise are stable across three different measurement occasions or semesters, especially the tutor's social congruence (Williams et al. 2011). The sixth study focuses on worksheets. This study demonstrates that a worksheet scaffold (i.e. a series of questions and information for the student to understand the processes described in the PBL problem) did not play a significant role in enhancing students' learning from the students' perspective and did also not play a significant role in recall of relevant concepts. The team dynamics, the tutor and the problem played a bigger scaffolding role in students' learning in the second year's students' opinions than the worksheet scaffold (Choo et al. 2011). The final, seventh study, deals with the role of reflection journal writing. An analysis of the frequency of various topical 
areas on which students chose to write when they were assigned to reflect on a question provided by the tutor on how and what was learned, only weakly correlates with students' academic performance (Lew and Schmidt 2011).

Overall it can be concluded from these studies that a clearly formulated problem, an especially socially congruent tutor, a cognitive congruent tutor with expertise, and a focused group discussion have a strong influence on students' learning and achievement, whereas the two other scaffolds-a worksheet or a reflection journal-do not play a significant role.

The findings from the studies focusing on the factors influencing students' learning and achievement in PBL are in line with previous studies in which the strong influence of the quality of PBL problems and the tutor on group functioning and student achievement in PBL were shown (Gijselaers and Schmidt 1990). PBL is aimed at actively engaging students in their learning by means of activating their prior knowledge, engaging them in elaboration, (i.e. generating meaningful relations between information) and stimulating their interest in seeking for new information (Schmidt et al. in press), using the discussion of PBL problems in small groups under guidance of a tutor.

\section{Strengths and limitations of the studies and further research}

The strengths of the studies reported in this special issue are that the studies all focus on the PBL process; they contribute towards a better understanding of the different PBL phases of initial problem discussing, self-study and reporting. The studies make clear that all these phases are important and build upon one other. Another strength is that the studies examine the relationship between aspects of the PBL process and students' learning, using conceptual recall, students' perceptions of their learning, and the results of students' achievement, in other words, both on process and outcome variables. Especially the concept-recall procedure, used in several of the studies, provides an innovative and unique approach to obtaining insight into the learning process in PBL. This procedure provides a new tool for further studies aimed at disentangling the PBL process, the why and how PBL works. A final strength is that the studies built upon each other in terms of measurement methods used, the focus on the different PBL phases and the investigation of different types of scaffolds in PBL.

When it comes to limitations of the studies, we need to keep in mind that the seven studies reported in this special issue were all conducted at the same Polytechnic in Singapore using a unique one-day-one-problem approach to PBL. On the one hand, this unique approach has many similarities to problem-based learning as applied at many medical schools all over the world; i.e. the use of three PBL phases, a carefully crafted problem, small group discussion, individual self-study, and tutor guidance and as such, it may be reasonable to generalize the results to multi-day PBL. On the other hand, the one-day-one problem approach to PBL seems to be more structured. Because only one problem is covered per day, problems are generally more focused and structured than the complex, multi-layered clinical cases used in most medical schools, particularly for students beyond initial entry levels. Given a more narrow problem focus, the tutor may be providing more guidance towards the learning issues that need to be covered by the students. These differences may limit the degree to which the findings can be generalized. For example, the lack of influence of the worksheet scaffold and the reflection journal scaffold may be due to the level of guidance offered by the tutor on what should be studied.

Further research is needed to investigate whether the conclusions drawn in this issue, especially in terms of scaffolds offered such as a worksheet and reflection journal, also 
hold for regular problem-based learning programs and across different learner levels. In addition, although the concept-recall procedure provides a new approach to obtaining insight into students' learning, it would also be worthwhile to not only count the numbers of concepts recalled, but also to explore how the student links the recalled concepts with one other in order to explore what the different PBL phases contribute towards a deep understanding of the subject-matter. So far, little is known about the self-study phase in PBL and whether PBL does indeed stimulate students to become better self-directed learners over the years.

\section{Implications for practice}

This new, more structured, one-day-one-problem PBL approach may be of interest for schools who have students who need more guidance and who are not yet ready to work less independently. The studies reported in this special issue again emphasize that it is important to develop PBL problems with clear indications of what is to be learned. Furthermore, this approach to PBL demonstrates that it is possible for a single tutor to actively engage a class of 25 students in their learning by using teams of five students and a combination of independent and tutor-facilitated work, similar to the format used in teambased learning (Michaelsen et al. 2008). The idea of splitting up a group of 25 students in smaller teams provides opportunities for all student to engage in valuable interactions, such as asking questions, answering questions, reasoning with each other, discussing contradictions, explaining in their own words, correcting misconceptions of others, and giving feedback to one another associated with effective learning (Dolmans and Schmidt 2006). Having students work together to prepare a presentation may also have a positive effect on learning, because students can help each other to clarify issues that are unclear and can support and motivate each other as is known from other studies of PBL (Hendry et al. 2005; Moust et al. 2005). Engaging students during PBL in designing a collaborative project has been successfully used by Bridges and Hallinger (1995) in graduate studies in education. Finally, the studies in this special issue demonstrate that when students in PBL are confronted with high quality PBL problems, the group can more or less do the work on its own and the tutor merely needs to ensure that students feel safe to ask questions of the tutor when needed, have resources at hand for self learning, and are developing a positive working relationship with the other students.

Acknowledgments Many thanks to the authors and co-authors of the studies included in this special issue, especially Jerome Rotgans who took the initiative for this special issue, and Jerome Rotgans and Henk Schmidt since they were involved as co-authors in many of the papers. Many thanks also to the reviewers of the seven papers for their valuable suggestions to further improve the papers published in this issue.

Open Access This article is distributed under the terms of the Creative Commons Attribution Noncommercial License which permits any noncommercial use, distribution, and reproduction in any medium, provided the original author(s) and source are credited.

\section{References}

Bridges, E. M., \& Hallinger, P. (1995). Implementing problem based learning in leadership development. Eugene, Oregon: ERIC Clearninghouse on Educational Management. 
Chng, E., Yew, E. H. J., \& Schmidt, H. G. (2011). Effects of tutor-related behaviours on the process of problem-based learning. Advances in Health Sciences Education. doi:10.1007/s10459-011-9282-7.

Choo, S. S. Y., Rotgans, J. I, Yew, E. H. J., \& Schmidt, H. G. (2011). Effects of worksheet scaffolds on student learning in problem-based learning. Advances in Health Sciences Education. doi:10.1007/ s10459-011-9288-1.

Dolmans, D. H. J. M., \& Schmidt, H. G. (2006). What do we know about cognitive and motivational effects of small group tutorials in problem-based Learning? Advances in Health Sciences Education, 11, 321-336.

Gijselaers, H. H., \& Schmidt, H. G. (1990). Development and evaluation of a causal model of problembased learning. In Z. M. Nooman, H. G. Schmidt, \& E. S. Ezzat (Eds.), Innovation in medical education. An evaluation of its present status (pp. 95-113). New Work: Springer.

Hendry, G. D., Hyde, S. J., \& Davy, P. (2005). Independent study groups. Medical Education, 39, 672-679.

Lew, M. D. N., \& Schmidt, H. G. (2011). Self-reflection and academic performance: Is there a relationship? Advances in Health Sciences Education. doi:10.1007/s10459-011-9298-Z.

Michaelsen, L. K., Parmelee, D. X., McMahon, K. K., Levine, R. E., \& Billings, D. M. (Eds.). (2008). Teambased learning for health professions education: A guide to using small groups for improving learning. Sterling, Virginia: Stylus Publishers.

Moust, J., Roebertsen, H., Savelberg, H., \& De Rijk, A. (2005). Revitalising PBL groups: Evaluating PBL with study teams. Education for Health, 18(1), 62-73.

Rotgans, J. I., O’Grady, G. O., \& Alwis, W. A. M. (2011). Introduction: studies on the learning process in the one-day, one problem approach to problem-based learning. Advances in Health Sciences Education. doi:10.1007/s10459-011-9299-y.

Rotgans, J. I., \& Schmidt, H. G. (2011). Cognitive engagement in the problem-based learning classroom. Advances in Health Sciences Education. doi:10.1007/s10459-011-9272-9.

Schmidt, H., Rotgans, j., \& Yew, E. (in press). The process of problem-based learning: What works and why.

Sockalingam, N., Rotgans, J. I., \& Schmidt, H. G. (2011). The relationships between problem-characteristics, achievement-related behaviors, and academic achievement in problem-based learning. Advances in Health Sciences Education. doi:10.007/s10459-010-9270-3.

Williams, J. C., Alwis, W. A. M., \& Rotgans, J. I. (2011). Are tutor behaviors in problem-based learning stable? A generalizability study of social congruence, expertise and cognitive congruence. Advanced in Health Sciences Education. doi:10.1007/s10459-011-9295-2.

Yew, A. H. J., Chng, E., \& Schmidt, H. G. (2010). Is learning in problem-based learning cumulative? Advances in Health Sciences Education. doi:10.007/s10459-010-9267-y. 